\title{
Motion sickness: more than nausea and vomiting
}

\author{
James R. Lackner
}

Received: 6 February 2014 / Accepted: 28 May 2014 / Published online: 25 June 2014

(C) The Author(s) 2014. This article is published with open access at Springerlink.com

\begin{abstract}
Motion sickness is a complex syndrome that includes many features besides nausea and vomiting. This review describes some of these factors and points out that under normal circumstances, many cases of motion sickness go unrecognized. Motion sickness can occur during exposure to physical motion, visual motion, and virtual motion, and only those without a functioning vestibular system are fully immune. The range of vulnerability in the normal population varies about 10,000 to 1 . Sleep deprivation can also enhance susceptibility. Systematic studies conducted in parabolic flight have identified velocity storage of semicircular canal signals-velocity integrationas being a key factor in both space motion sickness and terrestrial motion sickness. Adaptation procedures that have been developed to increase resistance to motion sickness reduce this time constant. A fully adequate theory of motion sickness is not presently available. Limitations of two popular theories, the evolutionary and the ecological, are described. A sensory conflict theory can explain many but not all aspects of motion sickness elicitation. However, extending the theory to include conflicts related to visceral afferent feedback elicited by voluntary and passive body motion greatly expands its explanatory range. Future goals should include determining why some conflicts are provocative and others are not but instead lead to perceptual reinterpretations of ongoing body motion. The contribution of visceral afferents in relation to vestibular and
\end{abstract}

\footnotetext{
J. R. Lackner

Volen Center for Complex Systems, Brandeis University, Waltham, MA 02454, USA

J. R. Lackner $(\square)$

Ashton Graybiel Spatial Orientation Laboratory, MS 033, Brandeis University, Waltham, MA 02454, USA

e-mail: lackner@brandeis.edu
}

cerebellar signals in evoking sickness also deserves further exploration. Substantial progress is being made in identifying the physiological mechanisms underlying the evocation of nausea, vomiting, and anxiety, and a comprehensive understanding of motion sickness may soon be attainable. Adequate anti-motion sickness drugs without adverse side effects are not yet available.

Keywords Motion sickness - Sopite syndrome ·

Adaptation · Vestibular function · Weightlessness · Visceral afferents

\section{Motion sickness is a complex syndrome}

Nausea and vomiting typically come to mind when people think of motion sickness. However, motion sickness comprises a much broader syndrome. Figure 1 shows a commonly used scale for identifying and rating symptoms of motion sickness. It includes a wide range of signs and symptoms including cold sweating, pallor of varying degrees, increases in salivation, drowsiness, headache, and even severe pain, as well as nausea and vomiting (Graybiel et al. 1968b). Other assessment scales rate sickness during exposure to visual or virtual stimulation and various forms of transport (Gianaros et al. 2001; Golding 1998; Golding and Gresty 2013; Kennedy et al. 1992a, b, Muth et al. 1996, Paillard et al. 2013). One facet of motion sickness that often is not recognized is the sopite syndrome (Graybiel and Knepton 1976, Lawson and Mead 1998; Matsangas and McCauley 2014a). It refers to the profound drowsiness and persistent fatigue that can follow brief exposures to highly provocative stimulation or prolonged exposures to low-intensity motion stimulation. Yawning has recently been shown to be a potential behavioral marker for onset 
DIAGNOSTIC CATEGORIZATION OF DIFFERENT LEVELS OF SEVERITY OF ACUTE MOTION SICKNESS

\begin{tabular}{|c|c|c|c|c|c|}
\hline Category & $\begin{array}{l}\text { Pathognomonic } \\
16 \text { points }\end{array}$ & $\begin{array}{l}\text { Major } \\
8 \text { points }\end{array}$ & $\begin{array}{l}\text { Minor } \\
4 \text { points }\end{array}$ & $\begin{array}{l}\text { Minimal } \\
2 \text { points }\end{array}$ & $\begin{array}{l}\text { AQS" } \\
1 \text { point }\end{array}$ \\
\hline Nausea syndrome & $\begin{array}{l}\text { Vomiting } \\
\text { or retching }\end{array}$ & Nausea* II, III & Nausea I & $\begin{array}{l}\text { Epigastric } \\
\text { discomfort }\end{array}$ & $\begin{array}{l}\text { Epigastric } \\
\text { awareness }\end{array}$ \\
\hline Skin color & & Pallor III & Pallor II & Pallor 1 & Flushing \\
\hline Cold sweating & & III & $\|$ & I & \\
\hline Increased salivation & & III & ॥ & 1 & \\
\hline Drowsiness & & III & $\|$ & 1 & \\
\hline Pain & & & & & Headache \\
\hline Central nervous system & & & & & $\begin{array}{l}\text { Dizziness: } \\
\text { Eyes closed } \geq \text { II } \\
\text { Eyes Open }\end{array}$ \\
\hline
\end{tabular}

"AQS = Additional qualifying symptoms. $\quad+\| I=$ severe or marked, $\|=$ moderate $. I=$ slight.

\begin{tabular}{|ccccc|}
\hline \multicolumn{4}{c}{ Levels of Severity Identified by Total Points Scored } \\
Frank Sickness & Severe Malaise & Moderate Malaise A & Moderale Malaise B & Slight Malaise \\
\hline (S) & (M III) & (M IIA) & (M IIB) & (M I) \\
$\geq 16$ points & $8-15$ points & $5-7$ points & $3-4$ points & $1-2$ points \\
\hline
\end{tabular}

Fig. 1 Cardinal signs and symptoms of motion sickness and criteria for grading motion sickness severity (Graybiel et al. 1968b)

of the sopite syndrome (Matsangas and McCauley 2014b). The sopite syndrome can persist for hours or even days and when exposure is prolonged even longer. It is characterized by boredom, apathy, failure of initiative, increased irritability, and even changes in personality. It may be one of the only syndromes that persist when nausea is not elicited or has abated.

Perhaps surprisingly, the drowsiness associated with the sopite syndrome has not been linked in laboratory studies to a decrease in sleep latency onset (Leslie et al. 1997). A recent study has shown that sleep deprivation increases susceptibility to motion sickness and impairs performance on many tasks, including the perceptual discrimination test (Kaplan et al. 2014). During severe motion sickness, although many manual performance and cognitive tasks are substantially impaired (Gresty et al. 2008; Gresty and Golding 2009), simple detection tasks such as the perceptual vigilance task (PVT) seem relatively unaffected (Kaplan et al. 2014).

\section{Much motion sickness goes unrecognized}

This is especially likely in recreational situations and under operational conditions in the military where neither the exposure conditions nor the individual's activity is tightly controlled. Symptoms that are actually characteristic of motion sickness may be interpreted as due to fatigue or just boredom when in fact they are being elicited by exposure to motion (Bronstein et al. 2013; Guingard and McCauley 1990; Lawther and Griffin 1986; Kennedy 1975). The point is that unless nausea and vomiting are elicited, decrements in performance may not even be recognized as being indicative of motion sickness (Lackner 1984). By contrast, under laboratory conditions, it is usually easy to recognize the onset of motion sickness because exposure conditions are carefully controlled, subjects are briefed with respect to the signs and symptoms, and stimulation intensity is generally high because the goal typically is to elicit sickness in a relatively brief period of time. Laboratory studies also involve trained observers who often can recognize the development of motion sickness in a subject prior to that individual even being aware that something untoward is happening.

Early investigators of motion sickness thought that there were two types of people: those who responded primarily to provocative stimulation with head symptoms such as headache and drowsiness, and gut responders who primarily experienced nausea and vomiting (Reason and Brand 1975). Now we know that an individual's response depends on the relative provocativeness of the stimulation, his or 
her relative susceptibility, and prior experience (Bos et al. 2005; Bronstein et al. 2013; Golding 1998, 2006; Golding and Gresty 2013; Golding and Stott 1997; O'Hanlon and McCauley 1974; Paillard et al. 2013). One important fact to recognize about motion sickness is that not all sickness is created equal (Lackner and Graybiel 1986c). For example, not all situations in which vomiting is elicited are equally discomforting for different individuals. Some people after vomiting feel total relief for a period of time. Others may have a much higher threshold for the induction of vomiting so that they are much more nauseated and disabled prior to vomiting, and then vomiting gives some relief, but only partial relief, and they still remain disabled (Graybiel and Lackner 1987). Some are unable to vomit even though the level of nausea they are experiencing is such that they are desperately eager to vomit. They may be more incapacitated than people who do vomit (Graybiel and Lackner 1980). Some subjects are progressively sensitized by repeated exposures to the same motion and become sick sooner but, the majority, show progressive adaptation over time and diminution of sickness (Graybiel and Lackner 1983).

Some individuals experience great anxiety as symptoms of motion sickness develop or even before by virtue of prior exposure or impending exposure to a provocative motion environment. (Jacob et al. 1993, 1995; Money 1970; Money et al. 1996; Yardley et al. 1994). This interrelationship has been recognized since very early times. Balaban and Jacob (2001) have provided a comprehensive review covering from the very earliest writings up to 2000.

\section{The rate of decay of symptoms is a key factor, influencing susceptibility and performance}

Decay of symptoms varies enormously across individuals. Some people on receiving provocative stimulation will show a very brief response, and others will maintain discomfort for a prolonged period. In our own studies, we have found that three key factors affect sickness development: sensitivity to stimulation, the rate of adaptation to stimulation (adaptation constant), and the time constant of decay of elicited symptoms (Ventura et al. 2014). We have found that the range of sensitivity in the general population varies about $10-1$, and the adaptation constant also ranges from 10 to 1 . By contrast, the decay time constant varies by 100-1. The import of these values is that susceptibility to motion sickness in the general population varies by about 10,000-1, a vast range.

The particular values of these three factors for a given individual can allow predictions of performance in different exposure conditions. For example, a person with high sensitivity to provocative motion but with a short decay constant and high rate of adaptation can-depending on the characteristics of a particular environment-experience less sickness and performance decrement than an individual with moderate sensitivity, but a long decay time constant, and a low rate of adaptability. The first individual will not show an integration or progression of symptoms with continued exposure, but will achieve adaptation quickly. The second will become progressively more motion sick because of the additive effects of continued exposure and failure to adapt.

Attempts to understand why there are such huge variations in sensitivity to motion stimulation and in decay rates have focused on factors such as estimates of sound loudness and the decay rates of the visual spiral aftereffect (Reason 1968) and asymmetries in ocular counter-rolling (Diamond and Markham 1991). Enhanced perception of sound loudness and persistence of visual spiral aftereffects were thought to reflect heightened sensitivity and persistence to sensory stimulation that might correlate with increased sensitivity to vestibular stimulation and hence susceptibility to motion sickness. Golding (2006) presents a critical review and analysis of attempts to relate susceptibility to a wide range of physical, physiological, and psychological factors. He emphasizes that, while there are many hypotheses and correlations, firm conclusions are lacking and broader knowledge of genetic factors will also be essential to a comprehensive understanding.

\section{Who is at risk for motion sickness?}

Experimental studies have shown that virtually anyone with normal vestibular function when exposed to provocative physical body motion, disruption of vestibulo-ocular reflexes, or optokinetic stimulation can to some extent be made motion sick. Graybiel (1970) found that blind individuals are as susceptible to motion sickness when exposed to provocative physical motion (Coriolis cross-coupling stimulation, see below) as sighted individuals who have their eyes closed, and their range of susceptibility tends to be comparable. Congenitally blind subjects lack vestibuloocular reflexes, such reflexes are present but abnormal in individuals with acquired blindness (Kompf and Piper 1987; Leigh and Zee 1980; Sherman and Keller 1986). The individuals tested by Graybiel varied over a broad range from congenital to late acquired blindness.

The only individuals not susceptible to motion sickness under virtually every condition so far explored are those with total loss of labyrinthine function (Cheung et al. 1991; Kellogg et al. 1965; Money and Cheung 1983; Dai et al. 2007; Johnson et al. 1999; Kennedy et al. 1968; Money 1990; Money et al. 1996). Such vestibular loss subjects also tend to be immune to the action of emetic drugs (Money and Cheung 1983). Normal individuals are not always equally 
susceptible to all forms of motion stimulation; some may be more susceptible to full field visual stimulation than vertical or horizontal oscillation of the body. Generally, there is a correlation of about .6-.8 between individual susceptibility in one motion environment and susceptibility in another (Golding 2006, Miller and Graybiel 1972).

The introduction of head-mounted displays and smart phones with sophisticated graphics to create virtual environments has led to great increases in visually induced motion sickness, including nausea and vomiting (DiZio and Lackner 2000; Lackner and DiZio 2003; McCauley and Sharkey 1992; Stanney et al. 1998; Hettinger and Riccio 1992; Kennedy et al. 1992a, b, 1993, 2010). In fact, nearly any situation that involves suppression of vestibulo-ocular reflexes is potentially provocative. For example, sea sickness and car sickness are triggered by the motion of the vehicle. When a person is reading or looking at something that is stable within the vehicle, it is necessary to suppress the vestibulo-ocular reflexes triggered by the vehicle's motion. In virtual environments that involve head tracking to update the visual scene, there are typically lags so that after the head begins moving, the visual array may not be updated until 60 or more msec later. Consequently, when the user moves eyes and head to focus on a peripheral area of the visual array, there will be a delayed visual sweep of the scene opposite the head movement, which provides optokinetic stimulation tending to drive the eyes off the desired fixation position. The user has to suppress this optokinetic reflex, and this can be extraordinarily provocative with a wide field of view display and time lags greater than about $60 / \mathrm{ms}$. Such delays lead not only to motion sickness, but also to an increase in duration of head movements and postural instability when the person is standing (DiZio and Lackner 1997, 2000, 2002). Suppression of vestibulo-ocular reflexes is even evocative of motion sickness when the individual's eyes in darkness. During exposure to angular acceleration, voluntary deviation of the eyes in the direction of the slow phase component of the reflexive eye movements is provocative and also increases the body displacement experienced (Evanoff and Lackner 1986; Quarck et al. 2009).

The introduction of smart phones and tablets with sophisticated graphics has also led to frequent reports of symptoms characteristic of motion sickness. Stoffregen et al. (2014) have described the important role of head and torso movements in eliciting symptoms.

\section{Any situation that requires altered control of the head and body is potentially provocative}

For example, on shipboard, passengers have to adopt a different way of standing and to anticipate the motion of the ship, which involves an altered pattern of neuromuscular activation to achieve desired upright stance, let alone to move about. Similarly, in the weightless conditions of space flight, the whole manner in which body orientation is controlled is altered. This changed control of the body and the alterations in vestibular function (unloading of the otolith organs) occurring in weightless conditions are extremely provocative during the first several days of space flight (Lackner and DiZio 1989, 2006; Lackner et al. 1991; Thornton and Bonato 2013).

On Earth, it is profoundly provocative to make pitch or roll head movements while rotating. Such head movements lead to a bizarre pattern of stimulation of the semicircular canals (Guedry and Graybiel 1962; Miller and Graybiel 1970a, b) and the generation of a Coriolis force on the head that will tend to deflect it from its intended path. Under normal non-rotating conditions when a head movement is made, the semicircular canals in the plane of head motion will be stimulated by the acceleration of the head. The endolymph in the canals will lag and displace the cupulae, but then as the head decelerates, the cupulae will be restored back to their rest position. The acceleration and deceleration of the head are typically completed in much less than one second. The neural output of the semicircular canals is then actually proportional to head velocity because the inertial and mechanical properties of the cupula-endolymph system essentially perform a mechanical integration. This head velocity signal is used to control compensatory eye movements that normally are appropriate for the situation. In addition, that signal is integrated to give an indication of the angular displacement of the head relative to space (Wilson and Melvill Jones 1979; Baloh and Honorubia 1990; Cohen et al. 1977, 1981).

The left side of Fig. 2, which illustrates only one member of each of the three pairs of bilaterally symmetric canals, shows that during exposure to a step change in horizontal angular velocity, the "yaw canal" cupula will be deflected and only gradually return to its rest position(Guedry and Benson 1978). Consequently, body rotation is felt and steadily decreases in magnitude until at point $\mathrm{B}$ the subject feels stationary again. But, when a pitch back head movement is made at $\mathrm{C}$, the yaw canal is tilted out of the plane of rotation and loses angular momentum so that it is stimulated in the opposite direction of that initially. The "roll canal" is brought into the plane of rotation and receives a step change in velocity so that it also responds for a prolonged time. The "pitch canal," by contrast, accurately signals the head movement that occurred in pitch. As a consequence of this unusual pattern of stimulation, the subject senses a complex pattern of body rotation and displacement, which persists until the canal signals decay back to baseline. This "Coriolis cross-coupling" stimulation is extremely disorienting and nauseogenic, and 
<smiles>CCC(CC)CC(C)C</smiles>
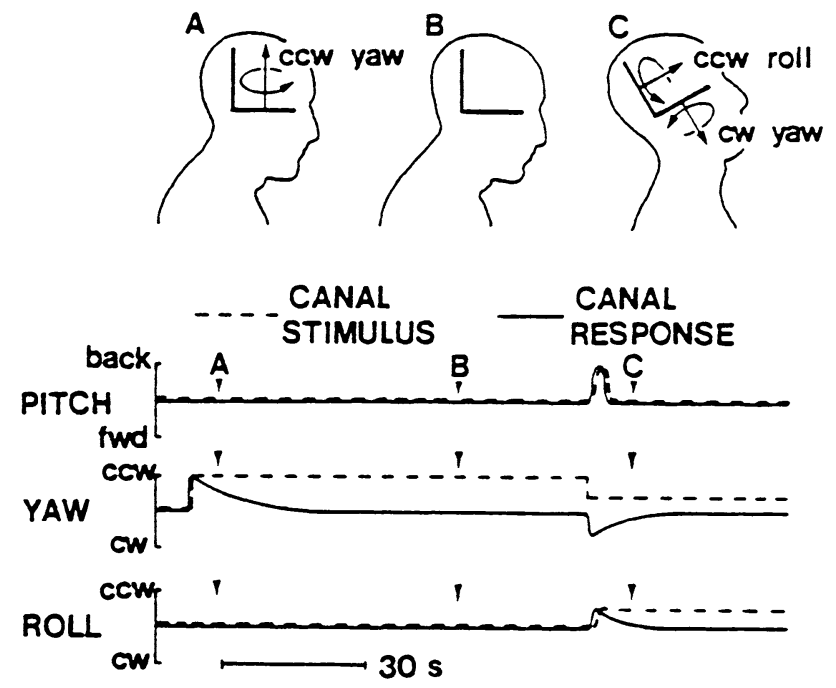

Fig. 2 Illustration of Coriolis cross-coupling stimulation

most people can only make a small number of head movements before becoming severely motion sick (Miller and Graybiel 1970a, b).

\section{Studies of space motion sickness enhance our understanding of terrestrial motion sickness}

In systematic studies of responses to Coriolis cross-coupling stimulation conducted in space flight, the Skylab 131 experiment, a startling result was obtained (Graybiel et al. 1975, 1977; Miller and Graybiel 1973). The participating astronauts had been tested preflight for their sensitivity to Coriolis cross-coupling stimulation and had been highly susceptible. Nine astronauts were tested over the course of the three manned Skylab missions. When tested in-flight each was totally insusceptible. Coriolis cross-coupling stimulation no longer "tumbled their gyros." Figure 3 shows the results of the Skylab 4 flight (Skylab 1 was an unmanned mission.). These findings presented a quandary. How could astronauts be susceptible preflight, but not during flight? A semicircular canal in terms of its mechanical properties should be gravity independent because the densities of the cupula and of the endolymph are each virtually one. Consequently, there is no gravity couple acting on the endolymph and cupula of a semicircular canal (Wilson and Melvill Jones 1979). Neither gravity nor gravitoinertial force level should directly influence canal neural output.

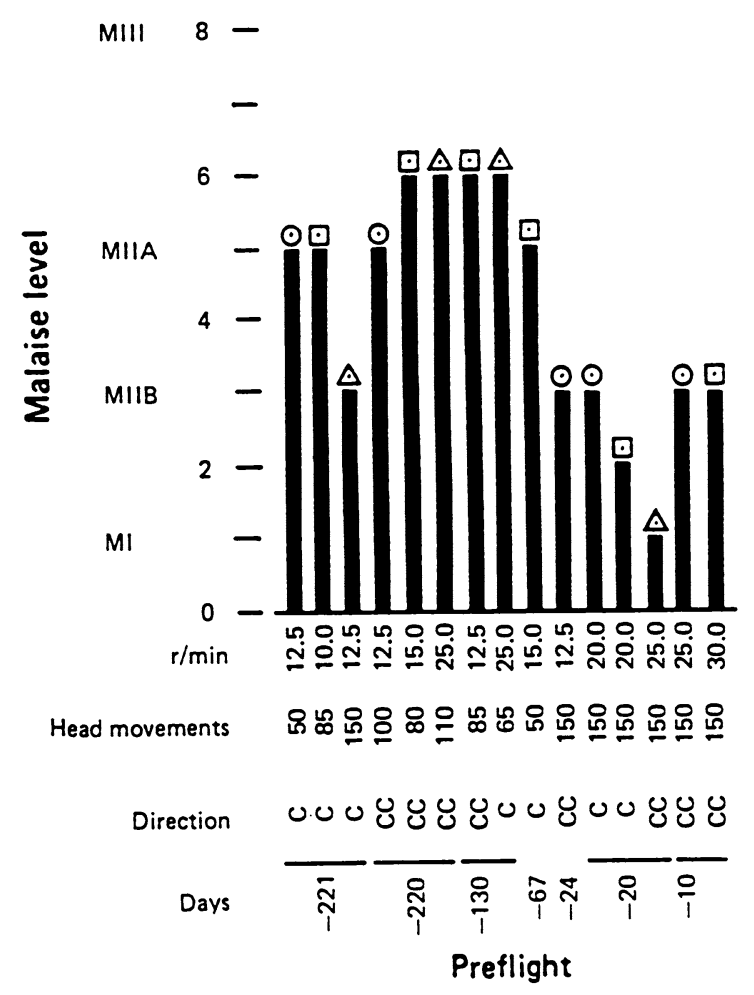

Fig. 3 Results of the Skylab M-131 experiment for the three Skylab 4 astronauts. The columns represent the severity of motion sickness on the Graybiel scale (see Fig. 1). The rows of numbers at the bottom
Skylab 4 astronaut

○ Commander

$\square$ Scientist Pilot $\triangle$ Pilot

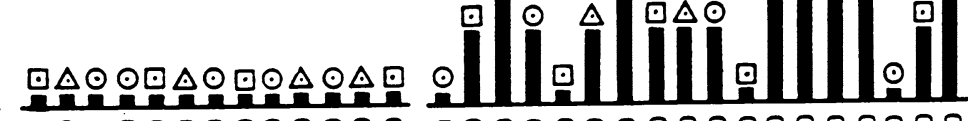

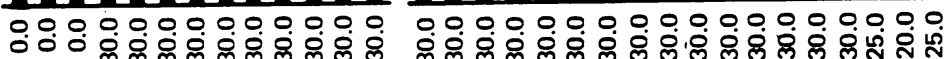

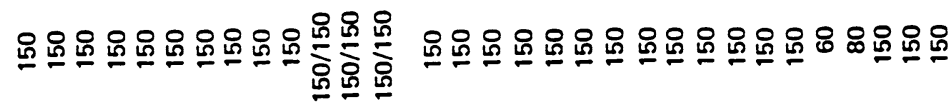

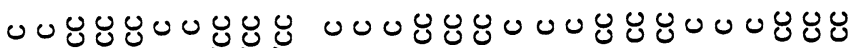

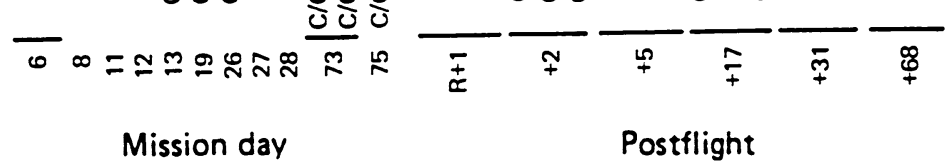

of the figure represent the angular velocity of body rotation in rpm, number of head movements made, rotation direction, and flight day 


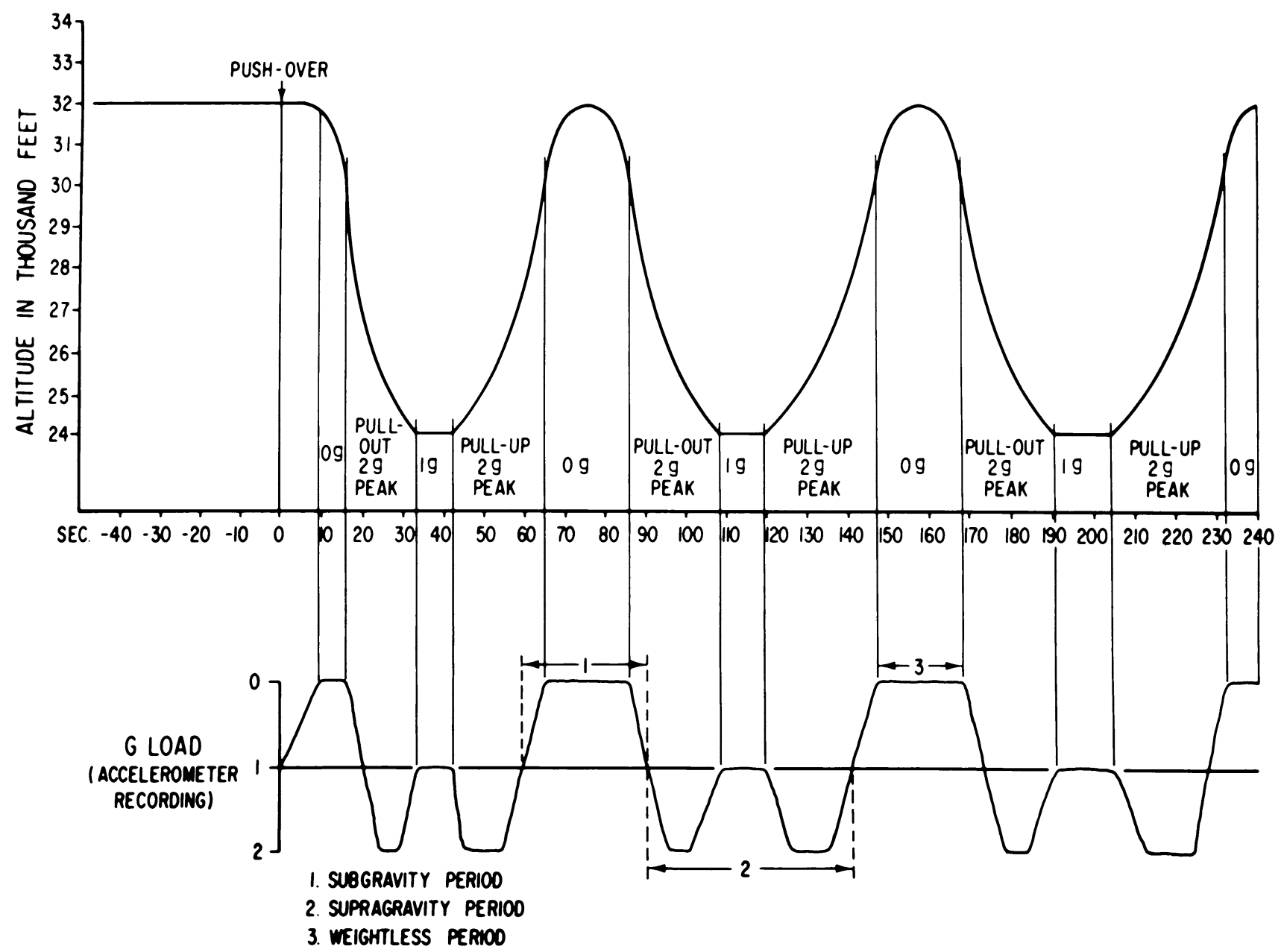

Fig. 4 Schematic flight profile of aircraft performing parabolic maneuvers to generate alternating period of free fall and increased gravito-inertial force

Studies were conducted in parabolic flight to determine the basis for the Skylab findings. Blindfolded subjects rotating at constant velocity made head movements while exposed to weightlessness $(0 \mathrm{~g})$, to straight and level flight, and to $2 \mathrm{~g}$ background force levels, where $g=9.8 \mathrm{~m} / \mathrm{s}^{2}$, the acceleration of Earth gravity (see Fig. 4). The results were unequivocal (Lackner and Graybiel 1984a, 1986a). Immediately on transition into $0 \mathrm{~g}$, head movements during rotation were less provocative and less nauseogenic than head movements made in straight and level flight. By contrast, head movements in $2 \mathrm{~g}$ were much more provocative than in level flight, and most subjects could only make a few before becoming nauseated to the point of vomiting. Moreover, being in weightlessness (" $0 \mathrm{~g}$ ") eliminated the disorienting effects of the head movements; the head movements felt nearly normal and were no more provocative than a head movement made in $0 \mathrm{~g}$ while not rotating (Lackner and Graybiel 1983, 1984b, 1985, 1986b).
Additional studies evaluated whether the velocity integration normally associated with canal stimulation to give a sense of angular spatial displacement was affected in $0 \mathrm{~g}$. It had already been found that the nystagmus that results from Coriolis cross-coupling stimulation was greatly suppressed in $0 \mathrm{~g}$ relative to $2 \mathrm{~g}$ (DiZio et al. 1987a), as was the nystagmus resulting from sudden-stop stimulation from constant velocity rotation (DiZio et al. 1987b). These findings raised the possibility that the central integration of the canal velocity signal was disrupted. To test this hypothesis, subjects were placed supine in a cradle-like device and used a joystick to indicate the amplitude of the angles through which they were turned when they were exposed to rotary angular accelerations an order of magnitude greater than threshold detection levels in 0,1 , and $2 \mathrm{~g}$ (Lackner and DiZio 2009).

Figure 5 shows that in $1 \mathrm{~g}$, the blindfolded subjects were accurate in indicating their angular displacement. By contrast, in $0 \mathrm{~g}$, they made a slight initial joystick movement in 

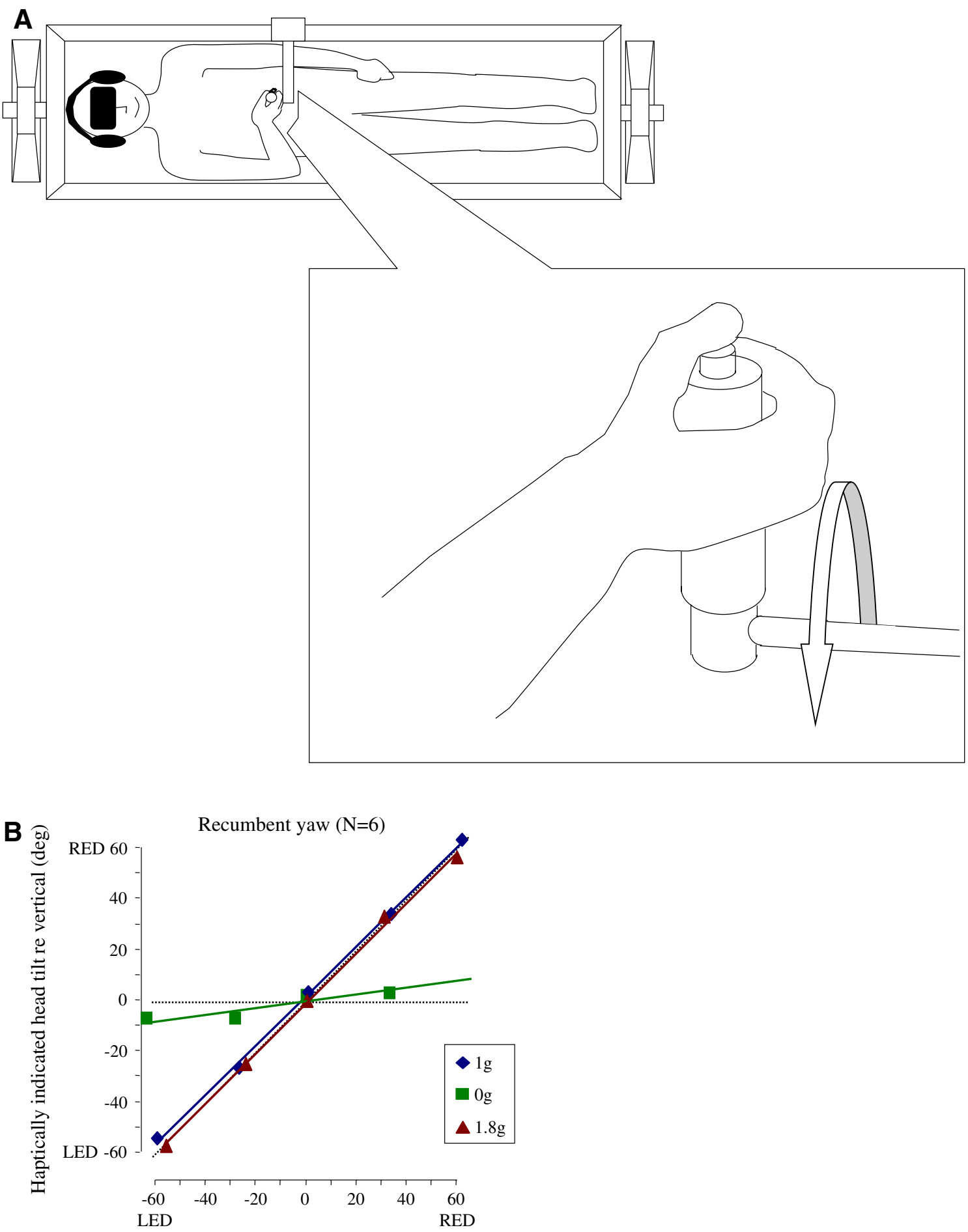

Head yaw angle relative to vertical $(\mathrm{deg})$

Fig. 5 Angular displacement perception as a function of gravito-inertial force level for recumbent yaw rotation. $L E D$ left ear down, $R E D$ right ear down

the direction of the turn, but then kept it aligned with their body axis because they did not feel any spatial displacement, just a slight initial tug in the direction they had actually been turned. These results mean that in a weightless environment, the signals from the semicircular canals are not being integrated by the central nervous system to give rise to a sense of body spatial displacement. It also explains why the Skylab astronauts were not susceptible to Coriolis 
cross-coupling stimulation in-flight. The signals that give rise to spatial displacement and lead to disorientation were not generated. It also explains why astronauts sometimes lose track of their orientation in space vehicles and may fail to recognize their spatial location when they make body turns (Lackner and DiZio 2000a).

During the Skylab M131 experiment, the astronauts were first tested on or after mission day 6. Coriolis crosscoupling stimulation was thought to be so provocative that in-flight testing was delayed for many days lest the astronauts become so motion sick that it would disrupt their other activities for days. During the initial days of the missions, the astronauts, however, did become motion sick simply by virtue of making head and body movements. Being in a weightless environment alters the sensory motor control of the head as an inertial mass, and we now know that such alterations are provocative per se (Lackner and DiZio 1989, 2006; Lackner and Graybiel 1980, 1986b; Oman 1987; Oman et al. 1986, 1990; Thornton and Bonato 2013). This altered control and need to recalibrate are a major factor in space motion sickness and terrestrial motion sickness experienced in vehicles as well.

The crucial point is that motor control is normally dynamically tuned and calibrated to the $1 \mathrm{~g}$ background force of earth. Whenever deviations or variations from this force level occur, motion sickness may result because of the disruption of vestibulo-ocular, optokinetic, and collic reflexes that need to be retuned. Motion sickness can persist until a new pattern of control of the head and eyes has been attained, and accommodation is made to the remapped relation between voluntary control of the head and body and the vestibular activity evoked (DiZio and Lackner 1997; Lackner and DiZio 1992, 2000a, b, 2006).

\section{Physiological mechanisms}

The physiological mechanisms underlying the elicitation and expression of motion sickness are complex and still not fully known (Yates et al. 1998). Miller and colleagues have identified the neural circuits controlling the respiratory and abdominal muscles during nausea and vomiting, and which brain areas are critical (Miller and Grelot 1996; Miller et al. 1990, 1994; Miller and Wilson 1983). Balaban has described the complex interrelationships between mechanisms subserving balance control and those related to anxiety and fear responses (Balaban 1996, 2002; Balaban and Thayer 2001). These pathways likely underlie the evocation of anxiety and dread some individuals experience as they begin to become motion sick. The relationship may actually be bidirectional, with anxiety and fear also enhancing the severity of motion sickness. Recently, the brain areas active during the development of nausea have been identified in imaging studies (Napadow et al. 2013; Sugiyama et al. 2011; Suzuki et al. 2012; Yates 1996a, b; Yates et al. 1995a, b; Yates and Bronstein 2005; Yates and Miller 2009).

Major recent progress has been made by Yates and his collaborators who have delineated the brain stem regions implicated in the elicitation of nausea and the control of the muscles involved in emesis. Yates et al. (2014) have provided a comprehensive description of the pathways involved in the evocation of nausea and vomiting. The pattern generator circuits involved in the actual act of vomiting have now been identified. Brain stem areas including the nucleus of the solitary tract (NTS), the dorsolateral reticular formation of the caudal medulla (lateral tegmental field, LTF), and the parabrachial nucleus (PB) together integrate signals that lead to nausea and vomiting. The detailed innervation and coordination of the diaphragm and abdominal muscles to evoke vomiting is now understood. During quiet breathing, their activity is in anti-phase, but during vomiting (and a range of activities involving postural stabilization), their activity is synchronized. Both PB and LTF responses are influenced by visceral afferents that also alter the responses to labyrinthine stimulation. NTS is the terminus of many visceral afferents and also receives efferent projections from the area postrema, which was once thought to be the primary "vomiting center." NTS is now known to relay signals to the emesis pattern generator circuit. Neurons in the vestibular cerebellum, including the fastigial nucleus (FN), are also influenced by visceral afferents. These regions may be implicated in triggering motion sickness, and Brooks and Cullen (2013) have recently shown that FN is very much involved in movement control and its adaptive updating.

In an elegant series of studies, Yates and his colleagues have shown the important role of the vestibular system in the regulation of respiration, heart rate, and compensations for changes in body orientation re gravity. For example, stimulation of cervical roots $\mathrm{C} 2$ and $\mathrm{C} 3$ alone affects the hypoglossus (tongue protrusion), but not respiration, whereas changes in head and body orientation elicit compensatory changes in respiration, as well as tongue protrusion (Bolton et al. 1998). This dichotomy ensures that changes in head orientation relative to a stationary torso are not conflated with head and torso changes re space (Moy et al. 2012).

Jian et al. $(2002,2005)$ have found that both somatic limb afferent stimulation and visceral afferent stimulation affect responses of cells in the vestibular nuclei during vertical rotation of the body in cats. In labyrinthectomized cats, even a larger percentage of the cells are affected. As the authors point out, the inputs of non-labyrinthine origin may be associated with and triggered by particular active behaviors. Yates et al. (2002) have shown that 
passive changes in body orientation with respect to gravity affect respiration. During shifts from supine to upright body orientation, the "length" of the diaphragm changes. The change in vestibular activity associated with going from a supine to erect orientation produces increases in diaphragm and abdominal muscle activity, which aid venous return. Labyrinthectomized animals lose this response, but recover it over time based on remaining signals about body orientation. Respiratory pump muscle activity is also affected by cerebellar regions receiving vestibular inputsthese influences can be excitatory or inhibitory, and it is uncertain whether they are engaged during voluntary movements.

Rice et al. (2010) have shown using rabies tracing techniques that cells in the inferior and lateral vestibular nuclei and in the medial pontomedullary reticular formation (MRF) influence diaphragm activity and project to the lumbar spinal cord. This pattern of connectivity suggests an influence on the integrative coordination of the diaphragm in situations involving voluntary (and perhaps passive) movements of the body. Yates and his collaborators have shown that there is a strong influence of visceral stimulation on the vestibular system (Arshian et al. 2013). Intragastric delivery of copper sulfate activates visceral afferents and can evoke both nausea and vomiting. These afferents also modulate, both up and down, the activity level of neurons in the caudal vestibular nucleus during vertical oscillation. Other areas of the vestibular system are even more affected by copper sulfate ingestions, with neuronal discharge levels increased. Other experiments by the Yates group have shown powerful influences of vestibular activity on respiration and heart rate (Yates et al. 2000). These findings together show how vestibular activity associated with body motion helps regulate heart rate and respiration.

The Yates studies together provide a long-needed basis for understanding why exposure to passive body motion may be provocative and why it is frequency dependent and dependent on body orientation re the direction of gravity (Anker et al. 2006; Rossiter et al. 1996; Wiker et al. 1979). For vertical oscillation, the most nauseogenic frequency is circa $.2 \mathrm{~Hz}$ (O'Hanlon and McCauley 1974). This value is below that for voluntary body movements involving locomotion and head or torso orienting movements. However, it is within the frequency of vertical motion experienced when riding a camel, which is notoriously provocative. Thus, there is rare human experience with vertical body motion at this frequency. Nevertheless, low frequency vertical oscillation will cause inertial lag of the viscera and excite a broad range of visceral mechanoreceptors. Recently, it has been shown that gut vagal afferents also influence anxiety and learned fear (Klarer et al. 2014).

\section{Theories of motion sickness}

Many theories of motion sickness have been proposed over the years. The evolutionary theory holds that motion sickness is essentially a response to poisoning (Money 1990; Treisman 1977). The notion is that when a noxious substance is ingested (e.g., rotting flesh) if nausea and vomiting result, inactivity will be induced and symptoms will be attenuated because of reduced levels of toxins circulated in the blood stream. Decreased activity enhances the possibility of recovery. This theory has empirical support. It is well known that people without functioning labyrinths are virtually immune to emetic drugs such as ipecac. Dogs have long been used in animal studies of motion sickness because their susceptibility patterns and emetic responses are similar to those of humans (Wang and Chinn 1956). The reactions of dogs to emetic drugs is usually greatly reduced or absent after they have been labyrinthectomized compared with their baseline responses (Money and Cheung 1983; Money et al. 1996).

A skeptic might argue that from an evolutionary standpoint susceptibility to motion sickness is actually a disadvantage. Evolutionary biologists long have recognized the need for balancing energy demands with the extent of body fatness and invoke the notion of set points for regulating "fatness." A complex set of hormones and receptors in the alimentary tract responds to digested foods and affects appetite drive. They also have influences on the nucleus of the solitary tract (NTS) as well as the arcuate nucleus of the hypothalamus, which can affect set points (da Silva et al. 2014; do Carmo et al. 2013; Sohn et al. 2013; Speakman 2014). The lower set point of body fatness-for regulating food intake-protects against death by starvation, whereas the upper set point limits body fatness, which lowers the risk of death by predation (Gosler et al. 2002, Higginson et al. 2012). In the evolutionary history of man, Australopithecus was heavily preyed on by dinofelis, a type of saber-toothed cat with especially strong forelimbs for grasping prey. It hunted paranthropus and homo habilis as shown by skulls found with the typical twin punctures delivered by saber canine teeth. Only with the acquisition of fire and tool use and weapons did death from predation become rare (Eller et al. 2009; Harding et al. 1997; Speakman 2014). Thus, from an evolutionary standpoint greatly limiting the capability to move by inducing nausea and vomiting would have decreased survival likelihood in the presence of prey. This alternative interpretation of the evolutionary theory would identify susceptibility to motion sickness as a pruning factor rather than a safety mechanism!

The ecological theory of motion sickness is based on the hypothesis that motion sickness is caused by postural instability, a loss of postural control (Riccio and Stoffregen 
1991). It is a corollary of the ecological theory of orientation that holds that perception of the upright is determined by the direction of dynamic balance (Stoffregen and Riccio 1988). The concept is that as postural instability increases, motion sickness will develop (Smart et al. 1998; Stoffregen and Smart 1998). Support for the ecological theory of orientation was derived from experiments in which blindfolded subjects used a joystick to set themselves to the "upright" by controlling a device programmed to mimic inverted pendulum behavior. The direction of balance of the device could be offset from the gravitational vertical by as much as $\pm 20^{\circ}$. With an offset direction of balance, the device's stability point does not correspond to the gravitational vertical. The experimental data indicated that subjects' settings of themselves to the upright were influenced by the apparatuses' direction of balance. These data seemed to confirm that dynamic balance influences the perceived upright.

Recently, the ecological theory of orientation was re-evaluated in experiments in which blindfolded subjects controlled a device with inverted pendulum dynamics whose direction of balance could be offset as much as $\pm 30^{\circ}$. Using a joystick, they set the device to four different instructed orientations: (1) the direction of gravity, (2) the upright, (3) the direction of least oscillation, and (4) the direction of balance. They also pressed the joystick trigger each time they were at the desired orientation (Panic et al. 2013a, b, 2014a, b). The attained settings of the apparatus were not different for the gravitational vertical and the upright, and corresponded to the results of Stoffregen and Riccio (1988). The joystick trigger presses, however, corresponded with the gravitational upright, not the direction of balance. By contrast, for setting the apparatus to the direction of balance and pressing the trigger, the attained and indicated settings were displaced in the direction of gravity. Subjects passively exposed to motion profiles of the device, which had been recorded when other subjects were actively controlling the device, were also accurate in indicating the direction of gravity with a trigger press. These results are in direct contradiction to the ecological theory of orientation and emphasize the importance of gravity rather than dynamic balance. Subjects sitting outside the device controlling it visually performed similar to subjects controlling it while in it.

Studies of the relationship between postural instability and onset of motion sickness also show little support for the ecological theory of motion sickness (Owen et al. 1998; Warwick-Evans and Beaumont 1991; Warwick-Evans et al. 1998). It is likely that the conditions in which postural instability precedes "motion sickness" are actually conditions in which postural hypotension is being elicited, hence symptoms such as "can't see straight, feeling dizzy," "hard to focus, everything is gray," and occasionally nausea
(Smart et al. 1998, 2002; Stoffregen et al. 2010; Villard et al. 2008). Typically, the ecological experiments involve prolonged visual fixation during passive upright stance at target distances that can range from .3 to $2 \mathrm{~m}$, or oscillation of the visual scene or surroundings. In similar conditions, we have had several episodes of full syncope. Subjects who are most affected tend to have low blood pressure. Controlled studies of balance and onset of motion sickness for exposure to virtual ship motion have shown the trend that motion sickness symptoms develop and then postural performance degrades (DiZio and Lackner 1997, 2000, 2002).

It is generally believed that the driver of a vehicle almost never becomes motion sick, whereas passengers may-and there is evidence to support this perspective (Rolnick and Lubow 1991). This viewpoint is consistent with a classic body of research supporting the view that active movement is essential in order to adapt to sensory rearrangemente.g., prism spectacles that displace the visual array or to develop normal sensory motor coordination (Held and Hein 1958, 1963). However, these studies failed to control for the role of attention. When active and passive exposure conditions are equated in terms of attention demandswhat the subjects are instructed to do-significant differences are typically absent or minimal Lackner 1981, Mather and Lackner 1981). Indeed, adaptation is minimal or absent when an individual makes movements that are perturbed and the instruction is to simply repeat the same movement; but if the instruction is to reach and attain a target goal, then adaptation is rapidly achieved (Kurtzer et al. 2003).

In "yoked paradigms," such as employed by Rolnick and Lubow (1991) where one individual initiates a movement and controls its parameters and the passive participant undergoes the same motion, it is important to have the subjects matched in terms of attentional demands and expected motion whether generated actively or passively. We have created a situation in which two subjects are seated side by side on a rotating device. One subject-the active subject rotates a handle mounted on a rheostat that activates the motor controlling the device. The passive subject's hand rests on a handle attached by a linkage to the active subjects control handle and passively receives indication of the physical motion forthcoming some milliseconds later. No difference in motion sickness susceptibility is present between active and passive subjects indicating being able to anticipate, actively or passively, impending motion is key. This ability to anticipate likely represents the ability of the cerebellum to predictively model the motion environment, is recently described by Bhanpuri et al. 2013 .

The sensory conflict theory of motion sickness proposed by Reason (1969, 1970, 1978; Reason and Brand 1975) was developed into a quantitative model by Oman (1982, 1990, 1998). It is the most widely accepted theory 
of motion sickness. Nearly all situations that elicit motion sickness involve some form of sensory motor conflict (Bles et al. 1998). Recent work by Cullen and colleagues on the cerebellar and vestibular mechanisms related to the control and appreciation of head and body movements has shown the important relationship between corollary discharge signals and reafferent signals associated with the resulting movement of the head or body. Any discrepancy between the expected and reafferent signals represents a sensory conflict that potentially could be provocative (Brooks and Cullen 2009, 2013; Cullen 2012; Cullen et al. 2009; Saab and Willis 2001; Serra et al. 1998).

Sensory conflict theories typically relate voluntary commands to the musculature (corollary discharge signals) to expected patterns of afferent signals (reafference) from vision, touch, hearing, proprioception and vestibular activity. However, it is important to realize that whenever arm movements, or virtually any whole body activity is executed the soft tissues of the body are also affected-e.g., lungs, kidneys, viscera, bladder, heart. For example, during activities in which surges in abdominal muscle activity and diaphragm activity increase pressure on the bladder and colon, anticipatory innervations of pelvic floor sphincter muscles are necessary to prevent leakage of urine and feces (Campbell et al. 2012; Hodges et al. 2007). Respiratory rhythms have to be appropriately entrained to locomotion to ensure efficient coordination of skeletal muscle activity and the "bouncing viscera" during running. Somatic afferent stimulation contributes to this entrainment, which can be prevented by blockade of the PB nucleus (cf Daley and Usherwood 2010; Porterfield 1985; Potts et al. 2005). Levinthal and Strick (2012) have shown that multiple motor and non-motor areas of cortex directly influence kidney function, including M1, M2, S1 and the insula. M1 and M2 have especially important contributions that arise from their respective trunk representation areas in motor cortex. These pathways provide a source of commands to somatic musculature as well as for sympathetic control of the kidneys.

Lovejoy (1988) has summarized some of the skeletal and muscular adaptations associated with visceral control during the transition to upright walking in Australopithecus ("Lucy"). Others have highlighted the way in which motion of the viscera is controlled by abdominal, diaphragm, and chest muscle activity during locomotion (Simons 1999). For example, during brachiation, a valsalva maneuver (forced expiration with closed air passages) is executed to rigidify the rib cage (Napier 1993; Wilson 1998). This allows the arms to exert against a stable base the substantial forces necessary to propel the body from branch to branch. The key point is that whenever a voluntary movement of the body is made many other motor compensations are simultaneously taking place outside of conscious awareness that are essential for the successful completion of the movement. These anticipatory postural compensations ensure stability of postural control and balance but also generate patterns of afferent feedback from both somatic and visceral receptors. Most of these afferents do not reach conscious awareness unless something goes awry. For example, an individual with a collapsed lung who makes an inspiratory movement may feel an empty space, a cavity in the chest. Many internal signals under normal circumstances are subject to sensory inhibition as so elegantly shown in von Bekesy's classic experiments (cf von Bekesy 1967). The point is that the nervous system precludes from consciousness many signals related to the background activity subserving specific volitional goals.

Sensory conflict theory must incorporate these ancillary signals from viscera and other internal organs when modeling the implications of exposure to conflict situations. For example, when on a moving vehicle such as a ship, getting one's "sea legs" involves being able to coordinate whole body movements to achieve desired goals in the moving environment while also maintaining appropriate predictable stabilization of the viscera. Visceral afferents, as discussed above, affect the control of respiration and heart rate and vestibular sensitivity to motion. Cerebellar mechanisms related to the formation of internal models of motor and sensory control thus have to incorporate models of the environment to which the organism is exposed and must adapt to, e.g., predictable vehicle motion. Here the concept of allostasis and the vestibulo-cerebellar and cerebellar-cortical reciprocal mechanisms involved in the regulation of the internal and the external motor and sensory milieus figure prominently (Bastian 2011; Bhanpuri et al. 2013; Brooks and Cullen 2009, 2013; Christensen et al. 2014; Criscimagna-Hemminger et al. 2010; Cullen 2012; McEwen and Wingfield 2010; Scott 1994; Strick et al. 2009; Wingfield 2003). The systematic pioneering work of Yates and his colleagues described above has shown the key importance of visceral and vestibular and cerebellar afferent signals in relation to motor ones in the adaptive maintenance of allostasis in different environments.

What remains perplexing, however, is why some conflicts are provocative and others are not. A common laboratory technique for studying motion sickness is to have subjects seated inside a large vertically striped drum. When the drum is rotated at constant velocity, it will soon be seen as being stationary and the subject will feel constant velocity self-rotation in the direction opposite that of the actual drum motion. Most subjects will develop symptoms of motion sickness within minutes (Hu and Stern 1998; Koch 1999; Lawson 1993; Stern et al. 1993, 1985, 1987). By contrast, if the subject is walking forward on a rotary treadmill moving in the same direction and at the same rate as the surrounding drum, no motion sickness will result (Lackner and DiZio 1988). Instead, the subject will feel 
voluntary self-motion in relation to a stationary drum, and the actual visual stimulation will be consistent with this. In other words, there is no conflict, and sensory conflict theory predicts no sickness. However, if the direction of the rotating drum is reversed while the subject continues making forward stepping movements on the treadmill, he or she will soon experience backwards motion. Some subjects in this circumstance feel that they are voluntarily making backwards stepping movements, others feel a paradoxical sense that their forward steps push them backwards. Despite the profound sensory conflict, no sickness is experienced, but instead, there is a central remapping of the subject's experienced activities that make them consistent with the visual flow. Surprisingly, subjects who make voluntary head movements during exposure to moving visual stimulation can prevent the induction of self-motion and prevent becoming motion sick (Lackner and Teixeira 1977).

\section{How can motion sickness be avoided or attenuated?}

The only sure cure is to avoid exposure to provocative situations entirely, or less desirably, to be without a functioning labyrinth. However, it is possible to introduce exposure gradually and initially limit activity in the novel environment. In fact, incremental exposure, progressively increasing the intensity of stimulation over multiple exposures, is a very effective way to prevent motion sickness (Graybiel and Wood 1969; Graybiel et al. 1969; Yen-Pik Sang et al. 2005).

A long series of pioneering experiments in the Pensacola slow-rotation room showed that it is possible to desensitize individuals by having them make head movements at very low velocities of rotation, e.g., $1 \mathrm{rpm}$, and then additional head movements at progressively higher velocities. With this paradigm, it is possible to adapt people to rotational velocities of $25 \mathrm{rpm}$, and even higher, without eliciting any symptoms of motion sickness. As a consequence of this exposure, the time constant of canal velocity storage is reduced. Motion sickness sensitivity is decreased for exposure to other forms of provocative stimulation as well (Cramer et al. 1978; Graybiel and Knepton 1978a, b; Graybiel et al. 1968a, b; Reason and Graybiel 1969, 1970).

This reduction in time constant of velocity storage is the factor that accounted for the absence of sensitivity to Coriolis cross-coupling stimulation in the weightless conditions in space flight and parabolic flight. The linear acceleration sensitive otolith organs that normally signal head orientation relative to gravity are unloaded in weightless conditions. A recent model of vestibular function indicates that in this circumstance, an otolith output specifying a determinate orientation would be absent and thus predicts velocity storage would be absent in $0 \mathrm{~g}$ (Bortolami et al. 2006). Vestibular loss subjects are immune to motion sickness as mentioned above and, of course, lack velocity storage.

Anti-motion sickness drugs potentially can enhance the rate of adaptation by allowing progressive exposure to higher levels of stimulation without symptoms being elicited (Cohen et al. 2008; Lackner and Graybiel 1994; Levine et al. 2000). With incremental exposure, people also can develop context specific adaptations so that, for example, they can move between a rotating artificial gravity environment and a stationary environment without either sensory motor control or motion sickness problems (Graybiel and Knepton 1978a, b; Lackner and DiZio 2000a, b, 2006). Drugs such as promethazine and scopolamine provide protective benefit (Bar et al. 2009; Davis et al. 1993; Graybiel and Lackner 1987; Gordon et al. 2001; Klocker et al. 2001; Nachum et al. 2001, 2006; Simmons et al. 2010). These drugs are central nervous system depressants and induce drowsiness so that they are often used in combination with dexedrine and ephedrine, respectively. In drug studies of motion sickness, there are always large placebo effects so that it is necessary to have both placebo and non-placebo controls. Placebo effects usually are on the order of 10-40 \% of drug effects (Wood and Graybiel 1968, 1969, 1970; Graybiel et al. 1976; Wood et al. 1986). Wrist acupressure bands and magnets sold to alleviate or prevent motion sickness potentially provide placebo benefits for some people. (Miller and Muth 2004). Ginger has also been touted as a remedy, but its effects are marginal (Lien et al. 2003). Autogenic feedback training has been used in conjunction with incremental exposure to increasingly provocative stimulation as a way of decreasing susceptibility to motion sickness (Cowings and Toscano 1982, 2000). Exposing subjects to visual-vestibular interactions has been shown to reduce their sensitivity to motion sickness during travel in transports such as buses (Dai et al. 2011). The procedure works by decreasing the time constant of velocity storage.

An important challenge for the future will be to try and develop drugs for preventing motion sickness that do not have undesirable side effects such as drowsiness. The sickness resulting from chemotherapy treatments involves visceral afferent activation. An important achievement will be to develop drugs that alleviate both nausea and vomiting, not just the vomiting elicited by chemotherapy (Yates et al. 2014).

Acknowledgments Support was provided by Air Force Office of Scientific Research Grant \#FA9550-12-1-0395.

Open Access This article is distributed under the terms of the Creative Commons Attribution License which permits any use, distribution, and reproduction in any medium, provided the original author(s) and the source are credited. 


\section{References}

Anker AR, Sadacca BF, Yates BJ (2006) Vestibular inputs to propriospinal interneurons in the feline $\mathrm{C} 1-\mathrm{C} 2$ spinal cord projecting to the C5-C6 ventral horn. Exp Brain Res 170:39-51. doi:10.1007/s00221-005-0186-8

Arshian MS, Puterbaugh SR, Miller DJ, Catanzaro MF, Hobson CE, McCall AA, Yates BJ (2013) Effects of visceral inputs on the processing of labyrinthine signals by the inferior and caudal medial vestibular nuclei: ramifications for the production of motion sickness. Exp Brain Res 228:353-363. doi:10.1007/ s00221-013-3568-3

Balaban CD (1996) Vestibular nucleus projections to the parabrachial nucleus in rabbits: implications for vestibular influences on the autonomic nervous system. Exp Brain Res 108:367-381

Balaban CD (2002) Neural substrates linking balance control and anxiety. Physiol Behav 77:469-475

Balaban CD, Jacob RG (2001) Background and history of the interface between anxiety and vertigo. J Anxiety Disord 15:27-51

Balaban CD, Thayer JF (2001) Neurological bases for balance-anxiety links. J Anxiety Disord 15:53-79

Baloh RW, Honorubia V (1990) Clinical neurophysiology of the vestibular system. FA Davis Co, Philadelphia

Bar R, Gil A, Tal D (2009) Safety of double-dose transdermal scopolamine. Pharmacotherapy 29:1082-1088. doi:10.1592/p hco.29.9.1082

Bastian AJ (2011) Moving, sensing and learning with cerebellar damage. Curr Opin Neurobiol 21:596-601. doi:10.1016/j.conb.2011.06.007

Bhanpuri NH, Okamura AM, Bastian AJ (2013) Predictive modeling by the cerebellum improves proprioception. J Neurosci 33:14301-14306. doi:10.1523/JNEUROSCI.0784-13.2013

Bles W, Bos JE, de Graaf B, Groen E, Wertheim AH (1998) Motion sickness: only one provocative conflict? Brain Res Bull 47:481-487

Bolton PS, Kerman IA, Woodring SF, Yates BJ (1998) Influences of neck afferents on sympathetic and respiratory nerve activity. Brain Res Bull 47:413-419

Bortolami SB, Rocca S, Daros S, DiZio P, Lackner JR (2006) Mechanisms of human static spatial orientation. Exp Brain Res 173:374-388. doi:10.1007/s00221-006-0387-9

Bos JE, MacKinnon SN, Patterson A (2005) Motion sickness symptoms in a ship motion simulator: effects of inside, outside, and no view. Aviat Space Environ Med 76:1111-1118

Bronstein AM, Golding JF, Gresty MA (2013) Vertigo and dizziness from environmental motion: visual vertigo, motion sickness, and drivers' disorientation. Semin Neurol 33:219-230. doi:10. 1055/s-0033-1354602

Brooks JX, Cullen KE (2009) Multimodal integration in rostral fastigial nucleus provides an estimate of body movement. J Neurosci 29:10499-10511. doi:10.1523/JNEUROSCI.1937-09.2009

Brooks JX, Cullen KE (2013) The primate cerebellum selectively encodes unexpected self-motion. Curr Biol 23:947-955. doi:10.1016/j.cub.2013.04.029

Campbell SE, Glazener CM, Hunter KF, Cody JD, Moore KN (2012) Conservative management for postprostatectomy urinary incontinence. Cochrane Database Syst Rev 1:CD001843. doi:10.1002/14651858.CD001843.pub4

Cheung BS, Howard IP, Money KE (1991) Visually-induced sickness in normal and bilaterally labyrinthine-defective subjects. Aviat Space Environ Med 62:527-531

Christensen A, Giese MA, Sultan F, Mueller OM, Goericke SL, Ilg W, Timmann D (2014) An intact action-perception coupling depends on the integrity of the cerebellum. J Neurosci 34:67076716. doi:10.1523/JNEUROSCI.3276-13.2014
Cohen B, Matsuo V, Raphan T (1977) Quantitative analysis of the velocity characteristics of optokinetic nystagmus and optokinetic after-nystagmus. J Physiol 270:321-344

Cohen B, Henn V, Raphan T, Dennett D (1981) Velocity storage, nystagmus, and visual-vestibular interactions in humans. Ann N Y Acad Sci 374:421-433

Cohen B, Dai M, Yakushin SB, Raphan T (2008) Baclofen, motion sickness susceptibility and the neural basis for velocity storage. Prog Brain Res 171:543-553. doi:10.1016/ S0079-6123(08)00677-8

Cowings PS, Toscano WB (1982) The relationship of motion sickness susceptibility to learned autonomic control for symptom suppression. Aviat Space Environ Med 53:570-575

Cowings PS, Toscano WB (2000) Autogenic-feedback training exercise is superior to promethazine for control of motion sickness symptoms. J Clin Pharmacol 40:1154-1165

Cramer DB, Graybiel A, Oosterveld WJ (1978) Successful transfer of adaptation acquired in a slow rotation room to motion environments in Navy flight training. Acta Otolaryngol 85:74-84

Criscimagna-Hemminger SE, Bastian AJ, Shadmehr R (2010) Size of error affects cerebellar contributions to motor learning. J Neurophysiol 103:2275-2284. doi:10.1152/jn.00822.2009

Cullen KE (2012) The vestibular system: multimodal integration and encoding of self-motion for motor control. Trends Neurosci 35:185-196. doi:10.1016/j.tins.2011.12.001

Cullen KE, Brooks JX, Sadehi SG (2009) How actions alter sensory processing: reafference in the vestibular system. Ann N Y Acad Sci 1164:29-36

da Silva AA, do Carmo JM, Wang Z, Hall JE (2014) The brain melanocortin system, sympathetic control, and obesity hypertension. Physiology (Bethesda) 29:196-202. doi:10.1152/phys iol.00061.2013

Dai M, Raphan T, Cohen B (2007) Labyrinthine lesions and motion sickness susceptibility. Exp Brain Res 178:477-487. doi:10.1007/s00221-006-0759-1

Dai M, Raphan T, Cohen B (2011) Prolonged reduction of motion sickness sensitivity by visual-vestibular interaction. Exp Brain Res 210:503-513. doi:10.1007/s00221-011-2548-8

Daley MA, Usherwood JR (2010) Two explanations for the compliant running paradox: reduced work of bouncing viscera and increased stability in uneven terrain. Biol Lett 6:418-421. doi: 10.1098/rsbl.2010.0175

Davis JR, Jennings RT, Beck BG, Bagian JP (1993) Treatment efficacy of intramuscular promethazine for space motion sickness. Aviat Space Environ Med 64:230-233

Diamond SG, Markham CH (1991) Prediction of space motion sickness susceptibility by disconjugate eye torsion in parabolic flight. Aviat Space Environ Med 62:201-205

DiZio P, Lackner JR (1997) Circumventing side effects of immersive virtual environments. In: Smith MJ, Salvendy G, Koulbeck RJ (eds) Advances in human factors/ergonomics. Design of computing systems, vol 21, Elsevier, Amsterdam, pp 893-896

DiZio P, Lackner JR (2000) Motion sickness side effects and aftereffects of immersive virtual environments created with helmetmounted visual displays. In: NATO RTO-MP-54, the capability of virtual reality to meet military requirements, pp 11-1-11-4

DiZio P, Lackner JR (2002) Proprioceptive adaptation and aftereffects. In: Stanney K (ed) Handbook of virtual environments. Lawrence Erlbaum Associates, NY, pp 751-771

DiZio P, Lackner JR, Evanoff JN (1987a) The influence of gravitoinertial force level on oculomotor and perceptual responses to Coriolis, cross-coupling stimulation. Aviat Space Environ Med 58:A218-A223

DiZio P, Lackner JR, Evanoff JN (1987b) The influence of gravitoinertial force level on oculomotor and perceptual responses 
to sudden stop stimulation. Aviat Space Environ Med 58:A224-A230

do Carmo JM, da Silva AA, Rushing JS, Pace B, Hall JE (2013) Differential control of metabolic and cardiovascular functions by melanocortin-4 receptors in proopiomelanocortin neurons. Am J Physiol Regul Integr Comp Physiol 305:R359-R368. doi:10.1 152/ajpregu.00518.2012

Eller E, Hawks J, Relethford JH (2009) Local extinction and recolonization, species effective population size, and modern human origins. 2004. Hum Biol 81:805-824. doi:10.3378/027.081.0623

Evanoff JN, Lackner JR (1986) Influence of voluntary ocular deviation on vestibular nystagmus. Acta Otolaryngol 102:450-456

Gianaros PJ, Muth ER, Mordkoff JT, Levine ME, Stern RM (2001) A questionnaire for the assessment of the multiple dimensions of motion sickness. Aviat Space Environ Med 72:115-119

Golding JF (1998) Motion sickness susceptibility questionnaire revised and its relationship to other forms of sickness. Brain Res Bull 47:507-516

Golding JF (2006) Motion sickness susceptibility. Auton Neurosci 129:67-76. doi:10.1016/j.autneu.2006.07.019

Golding JF, Gresty MA (2013) Motion sickness and disorientation in vehicles. In: Bronstein AM (ed) Oxford textbook of vertigo and imbalance. Oxford University Press, Oxford, pp 293-306

Golding JF, Stott JR (1997) Objective and subjective time courses of recovery from motion sickness assessed by repeated motion challenges. J Vestib Res 7:421-428

Gordon CR, Gonen A, Nachum Z, Doweck I, Spitzer O, Shupak A (2001) The effects of dimenhydrinate, cinnarizine and transdermal scopolamine on performance. J Psychopharmacol 15:167-172

Gosler AG, Greenwood JJD, Perrins C (2002) Predation risk and the cost of being fat. Nature 377:621-623. doi:10.1038/37762la0

Graybiel A (1970) Susceptibility to acute motion sickness in blind persons. Aerosp Med 41:650-653

Graybiel A, Knepton J (1976) Sopite syndrome: a sometimes sole manifestation of motion sickness. Aviat Space Environ Med 47:873-882

Graybiel A, Knepton J (1978a) Bidirectional overadaptation achieved by executing leftward or rightward head movements during unidirectional rotation. Aviat Space Environ Med 49:1-4

Graybiel A, Knepton J (1978b) Prevention of motion sickness in flight maneuvers, aided by transfer of adaptation effects acquired in the laboratory: ten consecutive referrals. Aviat Space Environ Med 49:914-919

Graybiel A, Lackner JR (1980) Evaluation of the relationship between motion sickness symptomatology and blood pressure, heart rate, and body temperature. Aviat Space Environ Med 51:211-214

Graybiel A, Lackner JR (1983) Motion sickness: acquisition and retention of adaptation effects compared in three motion environments. Aviat Space Environ Med 54:307-311

Graybiel A, Lackner JR (1987) Treatment of severe motion sickness with antimotion sickness drug injections. Aviat Space Environ Med 58:773-776

Graybiel A, Wood CD (1969) Rapid vestibular adaptation in a rotating environment by means of controlled head movements. Aerosp Med 40:638-643

Graybiel A, Thompson AB, Deane FR, Fregly AR, Colehour JK, Ricks EL Jr (1968a) Transfer of habituation of motion sickness on change in body position between vertical and horizontal in a rotating environment. Aerosp Med 39:950-962

Graybiel A, Wood CD, Miller EF, Cramer DB (1968b) Diagnostic criteria for grading the severity of acute motion sickness. Aerosp Med 39:453-455

Graybiel A, Deane FR, Colehour JK (1969) Prevention of overt motion sickness by incremental exposure to otherwise highly stressful coriolis accelerations. Aerosp Med 40:142-148
Graybiel A, Miller EF 2nd, Homick JL (1975) Individual differences in susceptibility to motion sickness among six Skylab astronauts. Acta Astronaut 2:155-174

Graybiel A, Knepton J, Shaw J (1976) Prevention of experimental motion sickness by scopolamine absorbed through the skin. Aviat Space Environ Med 47:1096-1100

Graybiel A, Miller EF 2nd, Homick JL (1977) Experiment M-131. Human vestibular function. NASA SP-377, US Govt Print Office, Washington, pp 74-103

Gresty MA, Golding JF (2009) Impact of vertigo and spatial disorientation on concurrent cognitive tasks. Ann N Y Acad Sci 1164:263-267. doi:10.1111/j.1749-6632.2008.03744.x

Gresty MA, Golding JF, Le H, Nightingale K (2008) Cognitive impairment by spatial disorientation. Aviat Space Environ Med 79:105-111

Guedry FE Jr, Benson AJ (1978) Coriolis cross-coupling effects: disorienting and nauseogenic or not? Aviat Space Environ Med 49:29-35

Guedry FE Jr, Graybiel A (1962) Compensatory nystagmus conditioned during adaptation to living in a rotating room. J Appl Physiol 17:398-404

Guingard JC, McCauley ME (1990) The accelerative stimulus for motion sickness. In: Crampton GH (ed) Motion and space sickness. CRC Press, Boca Raton, pp 123-152

Harding RM, Fullerton SM, Griffiths RC et al (1997) Archaic African and Asian lineages in the genetic ancestry of modern humans. Am J Hum Genet 60:772-789

Held R, Hein A (1958) Adaptation to disarranged hand-eye coordination contingent upon reafferent stimulation. Percept Mot Skills 8:87-90

Held R, Hein A (1963) Movement-produced stimulation in development of visually guided behavior. J Comp Physiol Psychol 56:872. doi:10.1037/H0040546

Hettinger LJ, Riccio GE (1992) Visually-induced motion sickness in virtual environments. Presence 1:306-310

Higginson AD, McNamara JM, Houston AI (2012) The starvationpredation trade-off predicts trends in body size, muscularity, and adiposity between and within Taxa. Am Nat 179:338-350. doi: $10.1086 / 664457$

Hodges PW, Sapsford R, Pengel LH (2007) Postural and respiratory functions of the pelvic floor muscles. Neurourol Urodyn 26:362-371. doi:10.1002/nau.20232

Hu S, Stern RM (1998) Optokinetic nystagmus correlates with severity of vection-induced motion sickness and gastric tachyarrhythmia. Aviat Space Environ Med 69:1162-1165

Jacob RG, Woody SR, Clark DB et al (1993) Discomfort with space and motion: a possible marker of vestibular dysfunction assessed by the Situational Characteristics Questionnaire. J Psychopathol Behav Assess 15:299-324

Jacob RG, Redfern MS, Furman JM (1995) Optic flow-induced sway in anxiety disorders associated with space and motion discomfort. J Anxiety Disord 9:411-425

Jian BJ, Shintani T, Emanuel BA, Yates BJ (2002) Convergence of limb, visceral, and vertical semicircular canal or otolith inputs onto vestibular nucleus neurons. Exp Brain Res 144:247-257. doi:10.1007/s00221-002-1042-8

Jian BJ, Acernese AW, Lorenzo J, Card JP, Yates BJ (2005) Afferent pathways to the region of the vestibular nuclei that participates in cardiovascular and respiratory control. Brain Res 1044:241250. doi:10.1016/j.brainres.2005.03.010

Johnson WH, Sunahara FA, Landolt JP (1999) Importance of the vestibular system in visually induced nausea and self-vection. J Vestib Res 9:83-87

Kaplan E, Ventura J, Pierobon A, Bakshi A, DiZio P, Lackner JR (2014) Influence of sleep deprivation on susceptibility to 
motion sickness and performance on cognitive and motor tasks (in preparation)

Kellogg RS, Kennedy RS, Graybiel A (1965) Motion sickness symptomatology of labyrinthine defective and normal subjects during zero gravity maneuvers. Aerosp Med 36:315-318

Kennedy RS (1975) Motion sickness questionnaire and field independence scores as predictors of success in naval aviation training. Aviat Space Environ Med 46:1349-1352

Kennedy RS, Graybiel A, McDonough RG, Beckwith RD (1968) Symptomology under storm conditions in the North Atlantic in control subjects and in person with bilateral labyrinthine defects. Acta Otolaryngol 66:533-540

Kennedy RS, Fowlkes JE, Berbaum KS, Lilienthal MG (1992a) Use of a motion sickness history questionnaire for prediction of simulator sickness. Aviat Space Environ Med 63:588-593

Kennedy RS, Lane NE, Lilienthal MG, Berbaum KS, Hettinger LJ (1992b) Profile analysis of simulator sickness symptoms: application to virtual environment systems. Presence 1:295-301

Kennedy RS, Lane NE, Berbaum KS, Lilienthal MG (1993) Simulator sickness questionnaire: an enhanced method for quantifying simulator sickness. Int J Aviat Psych 3:203-220

Kennedy RS, Drexler J, Kennedy RC (2010) Research in visually induced motion sickness. Appl Ergon 41:494-503. doi:10.1016/j.apergo.2009.11.006

Klarer M, Arnold M, Gunther L, Winter C, Lanhans W, Meyer U (2014) Gut vagal afferents differentially modulate innate anxiety and learned fear. J Neurosci 34:7067-7076

Klocker N, Hanschke W, Toussaint S, Verse T (2001) Scopolamine nasal spray in motion sickness: a randomised, controlled, and crossover study for the comparison of two scopolamine nasal sprays with oral dimenhydrinate and placebo. Eur J Pharm Sci 13:227-232

Koch KL (1999) Illusory self-motion and motion sickness: a model for brain-gut interactions and nausea. Dig Dis Sci 44:53S-57S

Kompf D, Piper HF (1987) Eye movements and vestibulo-ocular reflex in the blind. J Neurol 234:337-341

Kurtzer I, DiZio P, Lackner J (2003) Task-dependent motor learning. Exp Brain Res 153:128-132. doi:10.1007/s00221-003-1632-0

Lackner JR (1981) Some aspects of sensory-motor control and adaptation in man. In: Walk RD, Pick HL (eds) Intersensory perception and sensory integration. Plenum, New York, pp 143-173

Lackner JR (1984) Motion sickness: mechanisms, prevention, and treatment. In: Technical Evaluation Report A-C-, VII-X (ed)

Lackner JR, DiZio P (1988) Visual stimulation affects the perception of voluntary leg movements during walking. Perception 17:71-80

Lackner JR, DiZio P (1989) Altered sensory-motor control of the head as an etiological factor in space-motion sickness. Percept Mot Skills 68:784-786

Lackner JR, DiZio P (1992) Gravitational, inertial, and Coriolis force influence on nystagmus, motion sickness, and perceived head trajectory. In: Berthoz A, Graf W, Vidal PP (eds) The head-neck sensory-motor symposium. Oxford University Press, NY, pp 216-222

Lackner JR, DiZio P (2000a) Human orientation and movement control in weightless and artificial gravity environments. Exp Brain Res 130:2-26

Lackner JR, DiZio PA (2000b) Aspects of body self-calibration. Trends Cogn Sci 4:279-288

Lackner JR, DiZio P (2003) Cyber adaptation syndrome. In: Adelman G, Smith B (eds) Encyclopedia of neuroscience, CD-ROM, version edn. Elsevier Science, Amsterdam

Lackner JR, Dizio P (2006) Space motion sickness. Exp Brain Res 175:377-399. doi:10.1007/s00221-006-0697-y

Lackner JR, DiZio P (2009) Angular displacement perception modulated by force background. Exp Brain Res 195:335-343. doi:10.1007/s00221-009-1785-6
Lackner JR, Graybiel A (1980) Elicitation of motion sickness by head movements in the microgravity phase of parabolic flight maneuvers. Aviat Space Environ Med 55:513-520

Lackner JR, Graybiel A (1983) Etiological factors in space motion sickness. Aviat Space Environ Med 54:675-681

Lackner JR, Graybiel A (1984a) Elicitation of motion sickness by head movements in the microgravity phase of parabolic flight maneuvers. Aviat Space Environ Med 55:513-520

Lackner JR, Graybiel A (1984b) Influence of gravitoinertial force level on apparent magnitude of Coriolis cross-coupled angular accelerations and motion sickness. In: NATO-AGARD aerospace medical panel symposium on motion sickness: mechanisms, prediction, prevention and treatment. AGARD-CP372, vol 22, pp 1-7

Lackner JR, Graybiel A (1985) Head movements elicit motion sickness during exposure to microgravity and macrogravity acceleration levels. In: Igarashi M, Black FO (eds) Proceedings of the VII international symposium: vestibular and visual control of posture and locomotor equilibrium. Karger, Basel, pp 170-176

Lackner JR, Graybiel A (1986a) The effective intensity of Coriolis, cross-coupling stimulation is gravitoinertial force dependent: implications for space motion sickness. Aviat Space Environ Med 57:229-235

Lackner JR, Graybiel A (1986b) Head movements in non-terrestrial force environments elicit motion sickness: implications for the etiology of space motion sickness. Aviat Space Environ Med $57: 443-448$

Lackner JR, Graybiel A (1986c) Sudden emesis following parabolic flight maneuvers: implications for space motion sickness. Aviat Space Environ Med 57:343-347

Lackner JR, Graybiel A (1994) Use of promethazine to hasten adaptation to provocative motion. J Clin Pharmacol 34:644-648

Lackner JR, Teixeira RA (1977) Optokinetic motion sickness: continuous head movements attenuate the visual induction of apparent self-rotation and symptoms of motion sickness. Aviat Space Environ Med 48:248-253

Lackner JR, Graybiel A, DiZio PA (1991) Altered sensorimotor control of the body as an etiological factor in space motion sickness. Aviat Space Environ Med 62:765-771

Lawson BD (1993) Physiological responses to visually-induced motion sickness. In: vol Ph.D. Brandeis University, Waltham

Lawson BD, Mead AM (1998) The sopite syndrome revisited: drowsiness and mood changes during real or apparent motion. Acta Astronaut 43:181-192

Lawther A, Griffin MJ (1986) The motion of a ship at sea and the consequent motion sickness amongst passengers. Ergonomics 29:535-552. doi:10.1080/00140138608968289

Leigh RJ, Zee DS (1980) Eye movements of the blind. Invest Ophthalmol Vis Sci 19:328-331

Leslie KR, Stickgold R, Dizio P, Lackner JR, Hobson JA (1997) The effect of optokinetic stimulation on daytime sleepiness. Arch Ital Biol 135:219-228

Levine ME, Chillas JC, Stern RM, Knox GW (2000) The effects of serotonin (5-HT3) receptor antagonists on gastric tachyarrhythmia and the symptoms of motion sickness. Aviat Space Environ Med 71:1111-1114

Levinthal DJ, Strick PL (2012) The motor cortex communicates with the kidney. J Neurosci 32:6726-6731. doi:10.1523/JNEURO SCI.0406-12.2012

Lien HC, Sun WM, Chen YH, Kim H, Hasler W, Owyang C (2003) Effects of ginger on motion sickness and gastric slow-wave dysrhythmias induced by circular vection. Am J Physiol Gastrointest Liver Physiol 284:G481-G489. doi:10.1152/aj pgi.00164.2002

Lovejoy CO (1988) Evolution of human walking. Sci Am 259:118-125 
Mather JA, Lackner JR (1981) Adaptation to visual displacement: contribution of proprioceptive, visual, and attentional factors. Perception 10:367-374

Matsangas P, McCauley M (2014a) Yawning as a behavioral marker of mild motion sickness and sopite syndrome. Aviat Space Environ Med 85:658-661

Matsangas P, McCauley M (2014b) Sopite syndrome: A revised definition. Aviat Space Environ Med 85:672-673

McCauley MF, Sharkey TJ (1992) Cybersickness: perception of selfmotion in virtual environments. Presence 3:311-318

McEwen BS, Wingfield JC (2010) What is in a name? Integrating homeostasis, allostasis and stress. Horm Behav 57:105-111. doi:10.1016/J.Yhbeh.2009.09.011

Miller EF 2nd, Graybiel A (1970a) Motion sickness produced by head movement as a function of rotational velocity. Aerosp Med 41:1180-1184

Miller EF 2nd, Graybiel A (1970b) A provocative test for grading susceptibility to motion sickness yielding a single numerical score. Acta Otolaryngol Suppl 274:1-20

Miller EF 2nd, Graybiel A (1972) Semicircular canals as a primary etiological factor in motion sickness. Aerosp Med 43:1065-1074

Miller EF, Graybiel A (1973) Experiment M-131-Human vestibular function. Aerosp Med 44:593-608

Miller KE, Muth ER (2004) Efficacy of acupressure and acustimulation bands for the prevention of motion sickness. Aviat Space Environ Med 75:227-234

Miller AD, Wilson VJ (1983) Vestibular-induced vomiting after vestibulocerebellar lesions. Brain Behav Evol 23:26-31

Miller AD, Nonaka S, Lakos SF, Tan LK (1990) Diaphragmatic and external intercostal muscle control during vomiting: behavior of inspiratory bulbospinal neurons. J Neurophysiol 63:31-36

Miller AD, Nonaka S, Jakus J (1994) Brain areas essential or nonessential for emesis. Brain Res 647:255-264

Miller AD, Grelot L (1996) The neural basis of nausea and vomiting. In: Yates BJ, Miller AD (eds) Vestibular autonomic regulation. CRC Press, Boca Raton

Money KE (1970) Motion sickness. Physiol Rev 50:1-39

Money KE (1990) Motion sickness and evolution. In: Crampton GH (ed) Motion and space sickness. CRC Press, Boca Raton

Money KE, Cheung BS (1983) Another function of the inner-ear: facilitation of the emetic response to poisons. Aviat Space Environ Med 54:208-211

Money KE, Lackner JR, Cheung RSK (1996) The autonomic nervous system and motion sickness. In: Yates BJ, Miller AD (eds) Vestibular autonomic regulation. CRC Press, Boca Raton, pp 147-173

Moy JD, Miller DJ, Catanzaro MF et al (2012) Responses of neurons in the caudal medullary lateral tegmental field to visceral inputs and vestibular stimulation in vertical planes. Am J Physiol Regul Integr Comp Physiol 303:R929-R940. doi:10.1152/ajpr egu.00356.2012

Muth ER, Stern RM, Thayer JF, Koch KL (1996) Assessment of the multiple dimensions of nausea: the Nausea Profile (NP). J Psychosom Res 40:511-520

Nachum Z, Shahal B, Shupak A et al (2001) Scopolamine bioavailability in combined oral and transdermal delivery. J Pharmacol Exp Ther 296:121-123

Nachum Z, Shupak A, Gordon CR (2006) Transdermal scopolamine for prevention of motion sickness: clinical pharmacokinetics and therapeutic applications. Clin Pharmacokinet 45:543-566. doi:10.2165/00003088-200645060-00001

Napadow V, Sheehan JD, Kim J et al (2013) The brain circuitry underlying the temporal evolution of nausea in humans. Cereb Cortex 23:806-813. doi:10.1093/cercor/bhs073

Napier JR (1993) Hands. Princeton University Press, Princeton
O'Hanlon JF, McCauley ME (1974) Motion sickness incidence as a function of the frequency and acceleration of vertical sinusoidal motion. Aerosp Med 45:366-369

Oman CM (1982) A heuristic mathematical model for the dynamics of sensory conflict and motion sickness. Acta Otolaryngol Suppl 392:1-44

Oman CM (1987) Spacelab experiments on space motion sickness. Acta Astronaut 15:55-66

Oman CM (1990) Motion sickness: a synthesis and evaluation of the sensory conflict theory. Can J Physiol Pharmacol 68:294-303

Oman CM (1998) Sensory conflict theory and space sickness: our changing perspective. J Vestib Res 8:51-56

Oman CM, Lichtenberg BK, Money KE, McCoy RK (1986) M.I.T./ Canadian vestibular experiments on the Spacelab-1 mission: 4. Space motion sickness: symptoms, stimuli, and predictability. Exp Brain Res 64:316-334

Oman CM, Lichtenberg BK, Money KE (1990) Space motion sickness monitoring experiment: Spacelab 1. In: Crampton GH (ed) Motion and space motion sickness. CRC Press, Boca Raton, pp 217-246

Owen N, Leadbetter AG, Yardley L (1998) Relationship between postural control and motion sickness in healthy subjects. Brain Res Bull 47:471-474. doi:10.1016/S0361-9230(98)00101-4

Paillard AC, Quarck G, Paolino F, Denise P, Paolino M, Golding JF, Ghulyan-Bedikian V (2013) Motion sickness susceptibility in healthy subjects and vestibular patients: effects of gender, age and trait-anxiety. J Vestib Res 23:203-209. doi:10.3233/ VES-130501

Panic H, Panic AS, DiZio P, Lackner JR (2013a) Active control and perception of the vertical. Soc Neurosci Abstr 367:03

Panic H, Panic AS, DiZio P, Lackner JR (2013b) Visual and vestibular cues for orientation and balance. Soc Neurosci Abstr 367:04

Panic H, Panic AS, DiZio P, Lackner J (2014a) Dynamic balance and the perception of upright are dissociable $\mathrm{J}$ Neurophysiol (in submission)

Panic H, Panic AS, DiZio P, Lackner JR (2014b) Effect of gravity on active balance using visual or vestibular cues. J Neurophysiol (in submission)

Porterfield JA (1985) Dynamic stabilization of the trunk. J Orthop Sports Phys Ther 6:271-277

Potts JT, Rybak IA, Paton JF (2005) Respiratory rhythm entrainment by somatic afferent stimulation. J Neurosci 25:1965-1978. doi: 10.1523/JNEUROSCI.3881-04.2005

Quarck G, Lhuisset L, Etard O, Denise P (2009) Eye eccentricity modifies the perception of whole-body rotation. Exp Brain Res 196:295-301. doi:10.1007/s00221-009-1828-z

Reason JT (1968) Relations between motion sickness susceptibility spiral after-effect and loudness estimation. Br J Psychol 59:385

Reason JT (1969) Motion sickness-some theoretical considerations. Int J Man-Machine Stud 1:21-38

Reason JT (1970) Motion sickness: a special case of sensory rearrangement. Adv Sci 26:386-393

Reason JT (1978) Motion sickness adaptation: a neural mismatch model. J R Soc Med 71:819-829

Reason JT, Brand JJ (1975) Motion sickness. Academic Press, London

Reason JT, Graybiel A (1969) Adaptation to Coriolis accelerations: its transfer to the opposite direction of rotation as a function of intervening activity at zero velocity. NAMI-1086, NASA ORDER R-93. Naval Aerospace Medical Institute, Pensacola, FL

Reason JT, Graybiel A (1970) Progressive Adaptation to coriolis accelerations associated with 1-rpm increments in velocity of slow rotation room. Aerosp Med 41:73

Riccio GE, Stoffregen TA (1991) An ecological theory of motion sickness and postural instability. Ecol Psychol 3:195-240 
Rice CD, Weber SA, Waggoner AL, Jessell ME, Yates BJ (2010) Mapping of neural pathways that influence diaphragm activity and project to the lumbar spinal cord in cats. Exp Brain Res 203:205-211. doi:10.1007/s00221-010-2197-3

Rolnick A, Lubow RE (1991) Why is the driver rarely motion sickthe Role of controllability in motion sickness. Ergonomics 34:867-879. doi:10.1080/00140139108964831

Rossiter CD, Hayden NL, Stocker SD, Yates BJ (1996) Changes in outflow to respiratory pump muscles produced by natural vestibular stimulation. J Neurophysiol 76:3274-3284

Saab CY, Willis WD (2001) Nociceptive visceral stimulation modulates the activity of cerebellar Purkinje cells. Exp Brain Res 140:122-126

Scott GB (1994) Effects of short-term whole body vibration on animals with particular reference to poultry. Worlds Poult Sci J 50:25-38

Serra J, Azpiroz F, Malagelada JR (1998) Modulation of gut perception in humans by spatial summation phenomena. J Physiol 506(Pt 2):579-587

Sherman KR, Keller EL (1986) Vestibulo-ocular reflexes of adventitiously and congenitally blind adults. Invest Ophthalmol Vis Sci 27:1154-1159

Simmons RG, Phillips JB, Lojewski RA, Wang ZW, Boyd JL, Putcha L (2010) The efficacy of low-dose intranasal scopolamine for motion sickness. Aviat Space Environ Med 81:405-412. doi:10. 3357/Asem.2668.2010

Simons RS (1999) Running, breathing and visceral motion in the domestic rabbit (Oryctolagus cuniculus): testing visceral displacement hypotheses. J Exp Biol 202:563-577

Smart LJ, Pagulayan RJ, Stoffregen TA (1998) Self-induced motion sickness in unperturbed stance. Brain Res Bull 47:449-457. doi:10.1016/S0361-9230(98)00103-8

Smart LJ Jr, Stoffregen TA, Bardy BG (2002) Visually induced motion sickness predicted by postural instability. Hum Factors 44:451-465

Sohn JW, Harris LE, Berglund ED et al (2013) Melanocortin 4 receptors reciprocally regulate sympathetic and parasympathetic preganglionic neurons. Cell 152:612-619. doi:10.1016/j. cell.2012.12.022

Speakman JR (2014) If body fatness is under physiological regulation, then how come we have an obesity epidemic? Physiology 29:88-98. doi:10.1152/Physiol.00053.2013

Stanney K, Salvendy G, Deisinger J et al (1998) Aftereffects and sense of presence in virtual environments: formulation of a research and development agenda. Int J Hum Comput Interact 10:135-187. doi:10.1207/S15327590ijhc1002_3

Stern RM, Koch KL, Leibowitz HW, Linblad IM, Shupert CL, Stewart WR (1985) Tachygastria and motion sickness. Aviat Space Environ Med 56:1074-1077

Stern RM, Koch KL, Stewart WR, Lindblad IM (1987) Spectral analysis of tachygastria recorded during motion sickness. Gastroenterology 92:92-97

Stern RM, Hu SQ, Leblanc R, Koch KL (1993) Chinese hyper-susceptibility to vection-induced motion sickness. Aviat Space Environ Med 64:827-830

Stoffregen TA, Riccio GE (1988) An ecological theory of orientation and the vestibular system. Psychol Rev 95:3-14

Stoffregen TA, Smart LJ Jr (1998) Postural instability precedes motion sickness. Brain Res Bull 47:437-448

Stoffregen TA, Yoshida K, Villard S, Scibora L, Bardy BG (2010) Stance width influences postural stability and motion sickness. Ecol Psychol 22:169-191

Stoffregen TA, Chen YC, Koslucher FC (2014) Motion control, motion sickness, and the postural dynamics of mobile devices. Exp Brain Res 232:1389-1397. doi:10.1007/ s00221-014-3859-3
Strick PL, Dum RP, Fiez JA (2009) Cerebellum and nonmotor function. Annu Rev Neurosci 32:413-434. doi:10.1146/annurev.ne uro.31.060407.125606

Sugiyama Y, Suzuki T, DeStefino VJ, Yates BJ (2011) Integrative responses of neurons in nucleus tractus solitarius to visceral afferent stimulation and vestibular stimulation in vertical planes. Am J Physiol Regul Integr Comp Physiol 301:R1380-R1390. doi:10.1152/ajpregu.00361.2011

Suzuki T, Sugiyama Y, Yates BJ (2012) Integrative responses of neurons in parabrachial nuclei to a nauseogenic gastrointestinal stimulus and vestibular stimulation in vertical planes. Am J Physiol Regul Integr Comp Physiol 302:R965-R975. doi:10.1 152/ajpregu.00680.2011

Thornton WE, Bonato F (2013) Space motion sickness and motion sickness: symptoms and etiology. Aviat Space Environ Med $84: 716-721$

Treisman M (1977) Motion sickness: an evolutionary hypothesis. Science 197:493-495

Ventura J, DiZio P, Lackner J (2014) A simple test to predict susceptibility to motion sickness. In Preparation

Villard SJ, Flanagan MB, Albanese GM, Stoffregen TA (2008) Postural instability and motion sickness in a virtual moving room. Hum Factors 50:332-345

Von Bekesy G (1967) Sensory inhibition. Princeton University Press

Wang SC, Chinn HI (1956) Experimental motion sickness in dogs; importance of labyrinth and vestibular cerebellum. Am J Physiol 185:617-623

Warwick-Evans LA, Beaumont S (1991) An experimental evaluation of sensory conflict versus postural control theories of motion sickness. Ecol Psychol 7:163-179

Warwick-Evans LA, Symons N, Fitch T, Burrows L (1998) Evaluating sensory conflict and postural instability. Theories of motion sickness. Brain Res Bull 47:465-469

Wiker SF, Kennedy RS, Mccauley ME, Pepper RL (1979) Susceptibility to seasickness-influence of hull design and steaming direction. Aviat Space Environ Med 50:1046-1051

Wilson FR (1998) The hand: how its use shapes the brain, language, and human culture. Pantheon Books, New York

Wilson VJ, Melvill Jones G (1979) Mammalian vestibular physiology. Plenum Press, New York

Wingfield JC (2003) Control of behavioural strategies for capricious environments. Anim Behav 66:807-815. doi:10.1006/A nbe. 2003.2298

Wood CD, Graybiel A (1968) Evaluation of sixteen anti-motion sickness drugs under controlled laboratory conditions. Aerosp Med 39:1341-1344

Wood CD, Graybiel A (1970) A theory of motion sickness based on pharmacological reactions. Clin Pharmacol Ther 11:621-629

Wood CD, Manno JE, Manno BR, Odenheimer RC, Bairnsfather LE (1986) The effect of antimotion sickness drugs on habituation to motion. Aviat Space Environ Med 57:539-542

Yardley L, Luxon L, Lear S, Britton J, Bird J (1994) Vestibular and posturographic test results in people with symptoms of panic and agoraphobia. J Audiol Med 3:48-65

Yates BJ (1996a) Vestibular influences on cardiovascular control. In: Yates BJ, Miller AD (eds) Vestibular autonomic regulation. CRC Press, Boca Raton, pp 97-111

Yates BJ (1996b) Vestibular influences on the autonomic nervous system. Ann N Y Acad Sci 781:458-473

Yates BJ, Bronstein AM (2005) The effects of vestibular system lesions on autonomic regulation: observations, mechanisms, and clinical implications. J Vestib Res 15:119-129

Yates BJ, Miller DM (2009) Integration of nonlabyrinthine inputs by the vestibular system: role in compensation following bilateral damage to the inner ear. J Vestib Res 19:183-189. doi:10.3233/ VES-2009-0337 
Yates BJ, Balaban CD, Miller AD, Endo K, Yamaguchi Y (1995a) Vestibular inputs to the lateral tegmental field of the cat: potential role in autonomic control. Brain Res 689:197-206

Yates BJ, Siniaia MS, Miller AD (1995b) Descending pathways necessary for vestibular influences on sympathetic and inspiratory outflow. Am J Physiol 268:R1381-R1385

Yates BJ, Miller AD, Lucot JB (1998) Physiological basis and pharmacology of motion sickness: an update. Brain Res Bull 47:395-406

Yates BJ, Holmes MJ, Jian BJ (2000) Adaptive plasticity in vestibular influences on cardiovascular control. Brain Res Bull 53:3-9
Yates BJ, Billig I, Cotter LA, Mori RL, Card JP (2002) Role of the vestibular system in regulating respiratory muscle activity during movement. Clin Exp Pharmacol Physiol 29:112-117

Yates BJ, Catanzaro MF, Miller DJ, McCall AA (2014) Integration of vestibular and emetic gastrointestinal signals that produce nausea and vomiting: potential contributions to motion sickness. Exp Brain Res. doi:10.1007/s00221-014-3937-6

Yen-Pik Sang F, Billar J, Gresty MA, Golding JF (2005) Effect of a novel motion desensitization training regime and controlled breathing on habituation to motion sickness. Percept Mot Skills 101:244-256 